\title{
Probiotic fermented almond "milk" as an alternative to cow-milk yoghurt
}

\author{
Neus Bernata ${ }^{2}$, Maite Cháfera ${ }^{\mathrm{a}}$, Amparo Chiralta ${ }^{\mathrm{a}}$, And Chelo \\ GONZÁLEZ-MARTÍNEZ ${ }^{\mathrm{a}}$

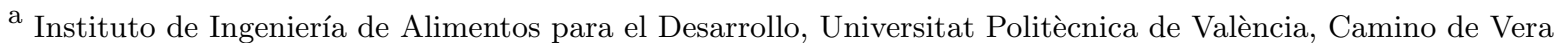 \\ s/n, 46022, Valencia, Spain. \\ ${ }^{*}$ Corresponding author \\ neuberpe@upvnet.upv.es \\ TEL: +3496387 7000
}

Received: 17 July 2014; Published online: 18 October 2015

Invited paper from the $3^{\text {rd }}$ International ISEKI_Food Conference - ISEKI_Food 2014 - Bridging Training and Research for Industry and the Wider Community - Food Science and Technology Excellence for a Sustainable

Bioeconomy

\begin{abstract}
Probiotics in almond-based matrices were considered as a means of obtaining fermented products which would cover both the current demand for health-promoting foods and for alternatives to standard yoghurts. Firstly, the combined effect of high pressure homogenisation (HPH) and heat treatment on the physical stability of almond "milk" was studied. The beverage was homogenised by applying 62 , 103 and $172 \mathrm{MPa}$ (MF1, MF2 and MF3 respectively); MF3 was also combined with two different heat treatments $\left(85^{\circ} \mathrm{C}-30 \mathrm{~min}(\mathrm{LH})\right.$ and $\left.121^{\circ} \mathrm{C}-15 \mathrm{~min}(\mathrm{HH})\right)$. Both microstructure and colloidal stability were analysed in all the processed samples to select the most suitable treatment with which to obtain a stable product. The selected almond milk was then fermented with probiotic Lactobacillus reuteri and Streptococcus thermophilus and the final product was characterised throughout cold storage time (28 days) as to $\mathrm{pH}$, acidity, serum retention and starter viability. A sensory evaluation and probiotic survival to in vitro digestion was also conducted. The results showed that the physical and structural almond-milk properties were affected by both HPH and heat treatments, obtaining the greatest stability in MF3-LH samples. The fermented milk permitted probiotic survivals above the level suggested as minimum for ensuring health benefits during the entire controlled time and, hence, can be considered as a functional food. No differences in the sensory acceptability of the product were found between 1 and 28 storage days. Therefore, a new, functional, fermented product was developed, which was suitable for targeted groups, such as the lactose-intolerant and cow-milk-protein allergic populations.
\end{abstract}

Keywords: Almond "milk"; Confocal; Physical stability; Probiotic; Survivals; Fermentation

\section{Introduction}

Vegetable "milks" are currently at the forefront due to either the growing problems related with intolerance (Fiocchi et al., 2010) or to changes in food preferences. Vegetable milks are emulsified products (the lipid content is dispersed in an aqueous phase), which means they are thermo- dynamically unstable and the selection of proper processing conditions plays a key role in its final stabilisation. Indeed, different process steps, such as homogenisation and heat treatments, usually produce changes in the arrangement of components, thus leading to modifications in the physical stability of the product. 
The most commonly-used homogenisation pressures in the food industry range between 20 and $50 \mathrm{MPa}$. The use of these pressures does not always ensure the physical stability of the emulsions and the reformulation of the product is usually needed, by means of the addition of different emulsifiers and/or stabilisers. The use of emerging technologies, such as high pressure homogenisation (HPH), may enhance the physical stability of the product, since it provokes the deflocculation of clusters of primary fat globules and the uniform dispersion of agglomerates, changes the protein conformation and increases the emulsion's viscosity, among other things (Floury, Desrumaux, \& Lardières, 2000; Pereda, Ferragut, Quevedo, Guamis, \& Trujillo, 2009; Desrumaux \& Marcand, 2002). Despite the advantages, current research, based on the application of $\mathrm{HPH}$ in the processing of vegetable milks, processing, has only focused on soy milk (Cruz et al., 2007; Li, Chen, Liu, \& Chen, 2008). There is a wide variety of vegetable milks available on the market but the same cannot be said for their yoghurt-like derivatives. If probiotic bacteria are used as starters, these fermented products would meet the current demand for health-promoting vegetable-based products. Probiotics are live microorganisms that, when administered in adequate amounts in edible matrices (i.e. food products), confer health benefits on the host (FAO/WHO, 2001), such as the reduction of hypercholesterolemia, the host immune modulation, the alleviation of constipation, the protection against traveller's diarrhoea, the protection against colon and bladder cancer, the prevention of osteoporosis or the modulation of food allergies (Saad, Delattre, Urdaci, Schmitter, \& Bressollier, 2013).

In particular, the so-called almond "milk" has long been used as an alternative to cow-milk for lacto-intolerant people, pregnant women and celiacs mainly due to their high levels of calcium, phosphorous and potassium (Luengo, 2009). Therefore, it could be used as a base product to develop new non-dairy fermented products with functional features, in which the nutritional and health benefits of almonds and probiotic bacteria are included. Almond nuts are rich in mono- and polyunsaturated fatty acids (mainly oleic and linoleic acids), vegetable proteins, dietary fibre, phytosterols, polyphenols, vitamins and minerals (Yada, Lapsley, \& Huang, 2011); most of which compounds have antioxidant properties and a proven beneficial effect on the plasma lipid profile, low-density lipoprotein oxidation and inflammatory processes, among other things (Liu, 2012; Egert, Kratz, Kannenberg, Fobker, \& Wahrburg, 2011; Jones et al., 2011).

The aim of this study was, on the one hand, to analyse the combined effect of heat treatments and high homogenisation pressures on the physical properties and stability of almond milk in order to define processing conditions which ensure the product quality and stability and, on the other hand, to develop a non-dairy, fermented, probiotic product with high quality properties by using L. reuteri ATCC 55730, a well-established probiotic (Casas \& Mollstam, 1997), mixed with S. thermophilus CECT 986.

\section{Materials and Methods}

\subsection{Preparation of almond milk}

The beverage was produced by soaking and grinding almonds (Prunus amygdalus L. var. dulcis) supplied by Frutos Secos 3G S.L. (Valencia, Spain). The extraction was carried out in Sojamatic 1.5 (Sojamatic ${ }^{\circledR}$; Barcelona, Spain), equipment specifically designed for the production of vegetable beverages, with a nut-water ratio of $8: 100$. The manufacturing process takes 30 minutes at room temperature. The milky liquid obtained was used as a control sample (untreated).

\subsection{High pressure homogenisation and heat treatments}

High pressure homogenisation ( $\mathrm{HPH}$ ) treatments were carried out in a high pressure homogeniser (M-110P model; Microfluidics International Corporation, USA) by applying 62,103 and $172 \mathrm{MPa}$ (samples MF1, MF2 and MF3 respectively). The homogeniser used runs in continuous mode and the retention time is very short (2-4 seconds). Raw almond milk and MF3 samples were submitted to a low temperature heat treatment at 85 
${ }^{\circ} \mathrm{C}$ for 30 min (known as LH and MF3LH, respectively) and to a high temperature heat treatment, $121{ }^{\circ} \mathrm{C}$ for $15 \mathrm{~min}(\mathrm{HH}$ and $\mathrm{MF} 3 \mathrm{HH})$. The heat treatment conditions chosen were those in which the destruction of all vegetative cells and enzymes are ensured (Walstra, Walstra, Wouters, \& Geurts, 2014).

\subsection{Fermented almond milk processing}

\section{Inoculum preparation}

Lactobacillus reuteri ATCC 55730 (Biogaia, Stockholm, Sweden) and Streptococcus thermophilus CECT 986 (CECT, Valencia, Spain) were activated from their frozen forms (stored in $40 \mathrm{~g} / 100 \mathrm{~mL}$ glycerol at $-\mathrm{f} 80{ }^{\circ} \mathrm{C}$ ), by transferring them to their selective broths until optimal bacterial growth is obtained. The selective broths were MRS (Scharlab, Barcelona, Spain) for the probiotic Lactobacillus and M17 (Biokar Diagnostics, Beauvais, France) for $S$. thermophilus. Incubation conditions were 37 ${ }^{\circ} \mathrm{C} / 24 \mathrm{~h} /$ anaerobically for $L$. reuteri, in which anaerobiosis was created by using anaerobic jars and a $\mathrm{CO}_{2}$-generator system (AnareroGenTM, Oxoid Ltd, Basingstoke, England) and 42 ${ }^{\circ} \mathrm{C} / 24 \mathrm{~h} /$ aerobically for $S$. thermophilus.

\section{Fermentation process}

Almond milks submitted to the fermentation process were enriched with $1.5 \%(\mathrm{w} / \mathrm{w})$ glucosefructose (Sosa Ingredients SL., Barcelona, Spain) prior to the inoculation process in order to improve the growth and acidification of the mixed culture used, based on previous studies (Bernat, Cháfer, González-Martínez, Rodríguez-García, \& Chiralt, 2014).

Strains in the exponential phase were centrifuged at $8,600 \mathrm{xg} / 10 \mathrm{~min} / 4^{\circ} \mathrm{C}$ to eliminate the selective broths. Immediately afterwards, each type of bacteria was resuspended in PBS-1x buffer (10 mmol/L phosphate, $137 \mathrm{mmol} / \mathrm{L} \mathrm{NaCl}, 2.7$ $\mathrm{mmol} / \mathrm{L} \mathrm{KCl}, \mathrm{pH}$ 7.4) separately until reaching concentrations of 108 colony forming units (cfu) per $\mathrm{mL} .3 \mathrm{~mL}$ of each suspension per $100 \mathrm{~mL}$ of processed almond milks were inoculated. The inoculated milk samples were then incubated at the optimal temperature of the mixed culture ( 40 ${ }^{\circ} \mathrm{C}$ ). When samples reached a $\mathrm{pH}$ of $\approx 4.6$, they were cooled to $4{ }^{\circ} \mathrm{C}$ (end of fermentation process) and stored at this temperature until the analyses were performed.

\subsection{Characterization of structural properties and stability of almond milk}

\section{Confocal laser scanning microscopy (CLSM)}

The microstructure of both raw and treated almond milks was analysed by means of CLSM, by using a Nikon confocal microscope C1 unit fitted on a Nikon Eclipse E800 microscope (Nikon, Tokyo, Japan). Fluorescent Rhodamine B dye (Fluka, Sigma-Aldrich, Missouri, USA) was used to stain proteins and carbohydrates, while Nile Red (Fluka, Sigma-Aldrich, Missouri, USA) was used to stain lipids, following the methodology described by Bernat et al. (2014).

\section{Colloidal stability of almond "milks"}

The colloidal stability of both raw and treated almond milks was determined via the phase separation analysis throughout the storage time (28 days) at $4{ }^{\circ} \mathrm{C}$. To this end, about $15 \mathrm{~g}$ of samples were poured into glass tubes of $16 \mathrm{~mm}$ in diameter and the height of the separate phases was quantified. $0.04 \mathrm{~g} / 100 \mathrm{~mL}$ of sodium azide (Panreac Química S.L.U., Barcelona, Spain) was added to the samples, to avoid any microbial growth during storage.

\subsection{Characterization of fermented almond-based products}

\section{pH and titratable acidity (TA)}

The $\mathrm{pH}$ of non-fermented and fermented almond samples was measured at $25{ }^{\circ} \mathrm{C}$ using a pH-meter (GLP 21+, Crison Instruments S.A.; Spain). The AOAC standard method was chosen to determine the TA in samples (AOAC 947.05), which consisted of a titration with 0.1

\begin{tabular}{l|l|l|l} 
IJFS | October 2015 | Volume 4 & pages 201-211
\end{tabular} 
mol/L NaOH solution (Panreac Química S.L.U., Barcelona, Spain), expressing the results as grams of lactic acid per L (Horwitz, 2000).

\section{Simulated gastrointestinal digestion (SGID)}

Fermented almond milk was submitted to a SGID. This in vitro digestion, done in triplicate, was performed as Glahn, Lee, Yeung, Goldman, and Miller (1998) described, but no demineralization was carried out. Porcine pepsin (800-2500 units/mg protein), pancreatin (activity, 41 USP specifications) and bile extract were purchased from Sigma-Aldrich ${ }^{\circledR}$ (St. Louis, MO, USA).

\section{Viability of starters}

The survival of both $L$. reuteri and $S$. thermophilus in fermented almond milks was quantified following the method described by the International Dairy Federation (International IDF Standard, 1997). The selective media used were MRS agar (Scharlab; Barcelona, Spain) for $L$. reuteri and M17 agar (Biokar Diagnostics, Beauvais, France) for S. thermophilus. The incubation conditions were $37{ }^{\circ} \mathrm{C} / 48 \mathrm{~h} /$ aerobically for S. thermophilus and $37{ }^{\circ} \mathrm{C} / 24 \mathrm{~h} /$ anaerobically for $L$. reuteri. Anaerobiosis was created by using anaerobic jars and a $\mathrm{CO}_{2}$-generator system (AnareroGen ${ }^{\mathrm{TM}}$; Oxoid Ltd, Basingstoke, England) and counts were reported as $\log \mathrm{cfu} / \mathrm{mL}$.

These analyses were done in fermented samples kept in chilled storage at different times and also, in the fermented samples submitted to a SGID.

\section{Serum retention capacity (SR)}

The SR of both non-fermented and fermented almond milks was analysed by sample centrifugation (Medifriger-BL, JP-Selecta; Spain). The conditions were $2,500 \mathrm{xg} / 45 \mathrm{~min} / 20^{\circ} \mathrm{C}$ and the amount of serum separation was used to quantify the sample stability.

\section{Sensory analysis}

A 16 member-strong trained panel evaluated almond-based fermented products after different storage times $\left(1,14\right.$, and 28 days) at $4{ }^{\circ} \mathrm{C}$. The members were selected on the basis of their interest, availability, lack of food allergies and their threshold to basic flavours. They were trained to score attributes of sweetness, acidity, almond flavour, consistency and mouthfeel and overall acceptability using interval scales that varied from 1 (slightly) to 5 (extremely).

The reference samples were used to set the interval scales for panel training. For the acidity reference, 1 and $2 \%$ of sucrose was added to commercial milk yoghurt, corresponding to 3 and 1 on the scale, respectively, and with $0.2 \%$ of citric acid corresponding to 5. Commercial milk yoghurt with 2, 5 and $14 \%$ of added sucrose levels was used for the sweetness evaluation, corresponding to 1,3 and 5 on the scale, respectively. For consistency and mouthfeel, liquid yoghurt, commercial soy dessert and Danone original ${ }^{\circledR}$ yoghurt were used as references, corresponding to 1,3 and 5 on the scale, respectively. For the almond flavour, the reference was the almond milk used in the study, which corresponded to 5 on the scale.

For the sensory analysis, each panellist tested 3 samples (cold stored for 0, 14 and 28 days, respectively) containing $6 \%$ of sucrose, in order to quantify the attributes in which each one was trained. The samples were randomly presented with a three digit code. The evaluation was conducted in a normalised tasting room at room temperature.

\section{Results and Discussion}

\subsection{Optimization of almond "milk" processing}

Figure 1 shows both the microstructure and initial macrostructure of almond milk, both untreated and submitted to different treatments (HPH and/or heat treatments). The oil droplets and protein bodies dispersed in the serum phase are clearly distinguished in the microstructure of untreated milk (Fig. 1A). A certain degree of protein flocculation was observed due to their hydrophobic character, since most almond proteins belong to the oleosin family, with low-molecular weight and poor water solubility (Beisson, Ferte, Voultoury, \& Arondel, 2001). This low water- 
affinity of proteins contributes to the poor stability of the obtained emulsions.

In LH samples (Fig. 1B), the majority of the almond proteins were aggregated. In many cases, protein aggregates included oil droplets which induce the formation of a weak gel, as was observed in the macrostructure.

The MF3 treatment greatly reduced the size of the fat globules (Fig. 1C). Nevertheless, most of the small particles were flocculated through protein bridges, which explains the poor stability of the emulsion despite the fact that particles are small in size. The poor stabilizing properties of the protein, associated with its high degree of hydrophobicity, is the cause of the flocculation process and subsequent phase separation, as was observed in the micrographs.

The MF3LH treatment caused the formation of big oil droplet-protein aggregates which appear embedded in a continuous protein matrix, thus enhancing the physical stability of the milk (Fig. $1 \mathrm{D})$. This new structure is the result of the combined effect of both treatments. MF reduces droplet size and promotes partial protein solubilisation (Cruz et al., 2007; Zhang, Li, Tatsumi, \& Isobe, 2005) and the heat treatments provoke protein denaturation and aggregation, giving rise to the formation of a 3D network which entraps big aggregates of the small protein-lipid particles (Walstra et al., 2014).

With regards to the macrostructure, all the samples showed phase separation after 1 storage day, except those submitted to MF3 and MF3LH treatments (Fig. 1). After 2 storage days, MF3 samples also exhibited phase separation. Once the separation process occurred in the different samples, no notable differences in the height of the separate phases were observed throughout storage period (data not shown). Nevertheless, samples submitted to MF3LH treatment were stable throughout the time studied. Therefore, the combined effect of homogenisation and thermal treatment seems to promote a weak gel formation (related to the formation of clusters), mainly associated with the protein solubilisation and subsequent denaturation during the thermal treatment, which contributed to the stabilisation of the particle dispersion, thus avoiding phase separation during the product storage. These cluster formations have also been observed in heated and homogenised cow milk (Walstra et al., 2014).

The observed behaviour indicates that, in almond samples submitted to HPH, the emulsifying properties of the proteins were not suitable for stabilising fat globules by interfacial protein adsorption, as observed in micrographs. Only when homogenised samples were submitted to thermal treatment and the proteins were denatured, did these help to stabilise the emulsions, mainly due to a viscous effect.

\subsection{Characterization vs. storage time of fermented processed almond "milk"}

\section{Probiotic survival}

As Buddington (2009) reviewed, health benefits that probiotics may exert are directly linked with, on the one hand, their ability to survive in the medium in which they are present and, on the other hand, their ability to survive in the gastrointestinal tract. Since a probiotic reduction is expected both in food matrices and once they are digested, a minimum number of viable probiotic bacteria of $107 \mathrm{cfu} / \mathrm{mL}$ has been strongly recommended by the time of consumption in order to effectively provide such health functionalities (Sanz \& Dalmau, 2008).

Figure 2 shows the viability of both $L$. reuteri and $S$. thermophilus in almond-based matrices after different cold storage times, in which statistical differences between storage times were also included by representing LSD intervals (95\% confidence level). As shown in Figure 2, the viability of both strains decreased throughout storage time $(\mathrm{p}<0.05)$, especially in the case of $S$. thermophilus. This last strain was used for technological purposes, since it is reported to improve the growth of lactobacilli (i.e. L. reuteri) (Tamime \& Robinson, 1999); hence its viability was not as relevant as the probiotic strain. $L$. reuteri counts were above the minimum level recommended $\left(10^{7} \mathrm{cfu} / \mathrm{mL}\right)$ throughout storage time, which ensured the potential probiotic functionalities. Therefore, the fermented product developed, owing to the presence of the probiotic $L$. reuteri, could be used for the reduction of in-

\begin{tabular}{l|l|l|l} 
IJFS | October 2015 | Volume 4 & pages 201-211
\end{tabular} 

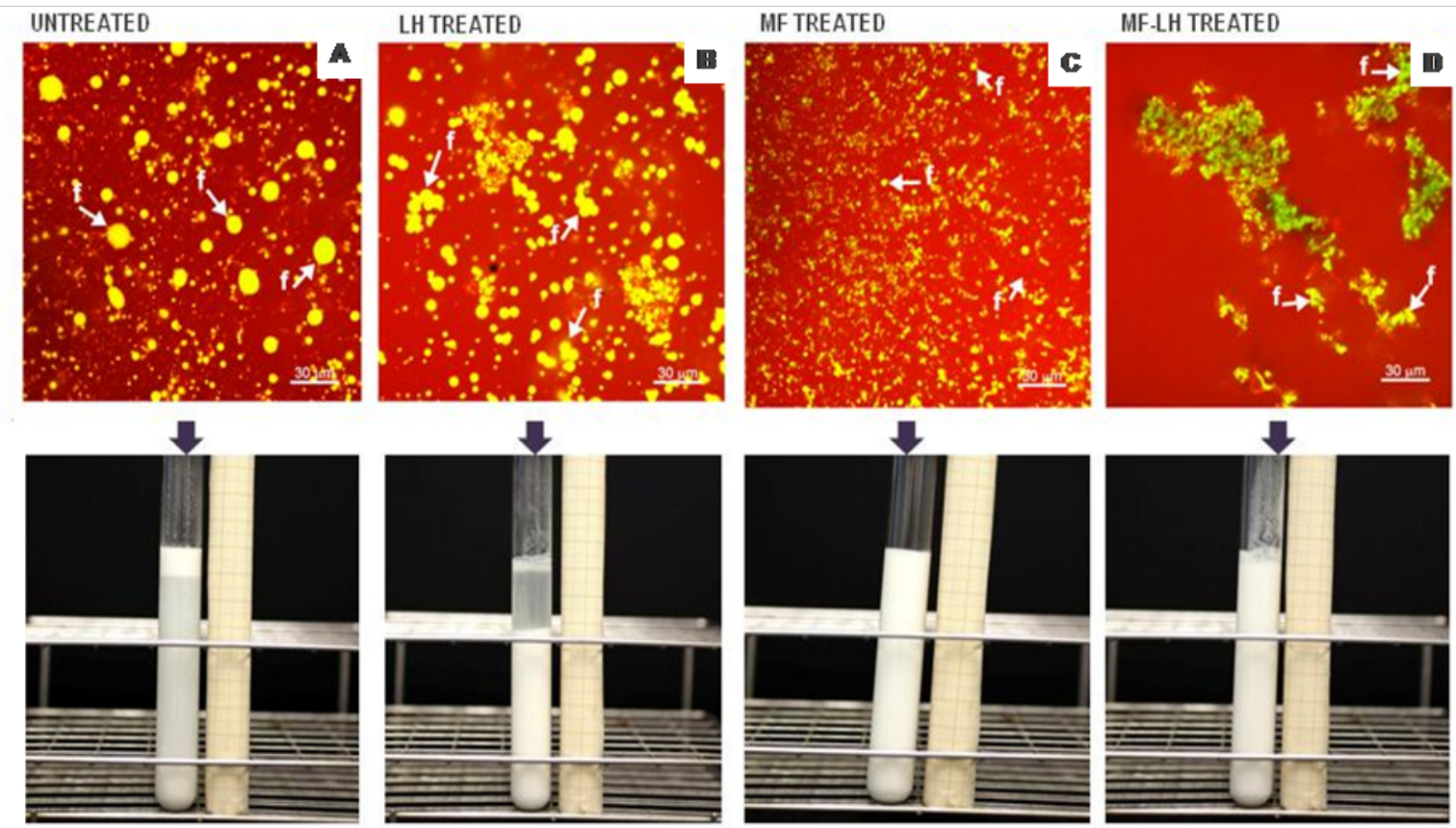

Figure 1: Microstructure (CLSM micrographs) and macrostructure (Canon images) of almond "milk" untreated (A), low heat treated ( $\mathrm{LH})(\mathrm{B})$, homogenised at $172 \mathrm{MPa}(\mathrm{MF})(\mathrm{C})$ and treated by combined MF-LH (D). f: fat

fantile colic and improvements feeding tolerance (Savino, Pelle, Palumeri, Oggero, \& Miniero, 2007; Indrio et al., 2008), the reduction of constipation (Coccorullo et al., 2010) and modulation of certain cytokines involved in atopic diseases (Miniello et al., 2010).

As regards the in vitro digestion assays carried out, the viability of the probiotic bacteria after SGID was remarkably high, as more than $50 \%$ of the $L$. reuteri present in the fermented almond milk was able to survive against gastro-intestinal enzymes $(p<0.05)$, which reinforces the functionality of the product.

\section{Antioxidant Capacity}

Table 1 shows the $\mathrm{pH}$, titratable acidity (TA) and serum retention capacities (SR) after sample centrifugation of both non-fermented and fermented almond milks. As can be seen, the $\mathrm{pH}$ values were kept constant throughout the storage time, which averaged 4.65. Although the
TA increased over storage time, from the $7^{\text {th }}$ day onwards the differences between the values were non-significant $(\mathrm{p}<0.05)$, being around 2.2 $\mathrm{g} / \mathrm{L}$. This low TA value might have a positive effect on the overall sensory acceptance of the final product, since it is a critical feature in yoghurts (Tamime \& Robinson, 1999).

As far as the SR values (Table 1) are concerned, a greater serum separation was quantified in nonfermented samples, while very few differences were observed in the case of fermented samples stored for different lengths of time. This new, weak gel structure was formed in the fermented product as a result of the flocculation of dispersed particles caused by to the action of proteins and these results suggest that it was able to better retain part of the serum present in the almond milk. 


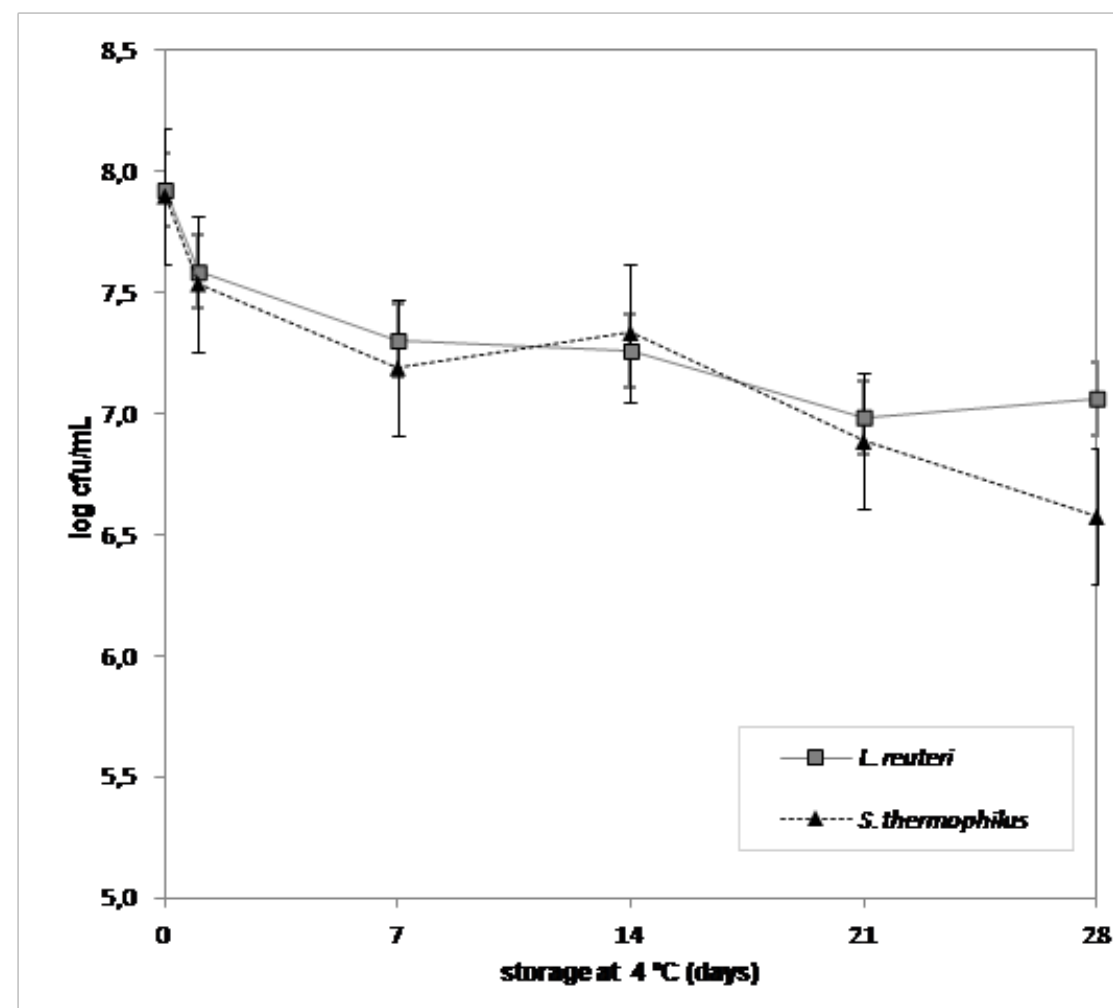

Figure 2: Viability of both L. reuteri (grey line) and S. thermophilus (dashed black line) in fermented almond milk after different cold storage times $(0,1,7,14,21$ and 28 days). Statistical differences between storage times were also included by representing LSD intervals (95\% confidence level)

Table 1: Values of $\mathrm{pH}$, titratable acidity (TA) and serum retention capacity (SR) of both processed almond "milk" (MF3LH) and fermented derived product (FP) throughout storage time (days) at $4{ }^{\circ} \mathrm{C}$

\begin{tabular}{cccc}
\hline Sample & pH & TA (g/L of lactic acid) & SR (\% (v/v) of precipitate) \\
\hline MF3LH & $6.567(0.006)$ & $0.39(0.03)$ & $36(2)$ \\
\hline FP 1 d & $4.657(0.012)^{a}$ & $1.90(0.12)^{a}$ & $43(2)^{a b c}$ \\
FP 7 d & $4.63(0.02)^{b}$ & $2.23(0.09)^{b}$ & $42(3)^{b c}$ \\
FP 14 d & $4.657(0.006)^{a}$ & $2.23(0.0)^{b}$ & $39(0.7)^{c}$ \\
FP 21 d & $4.633(0.012)^{b}$ & $2.19(0.07)^{b}$ & $45(3)^{a b}$ \\
FP 28 d & $4.650(0.019)^{a b}$ & $2.26(1.0)^{b}$ & $48(3)^{a}$ \\
\hline
\end{tabular}

${ }^{a, b, c}$ Different letters in same column indicates significant differences between samples analysed at $95 \%$ confidence levels

IJFS | October 2015 | Volume 4 | pages 201-211 


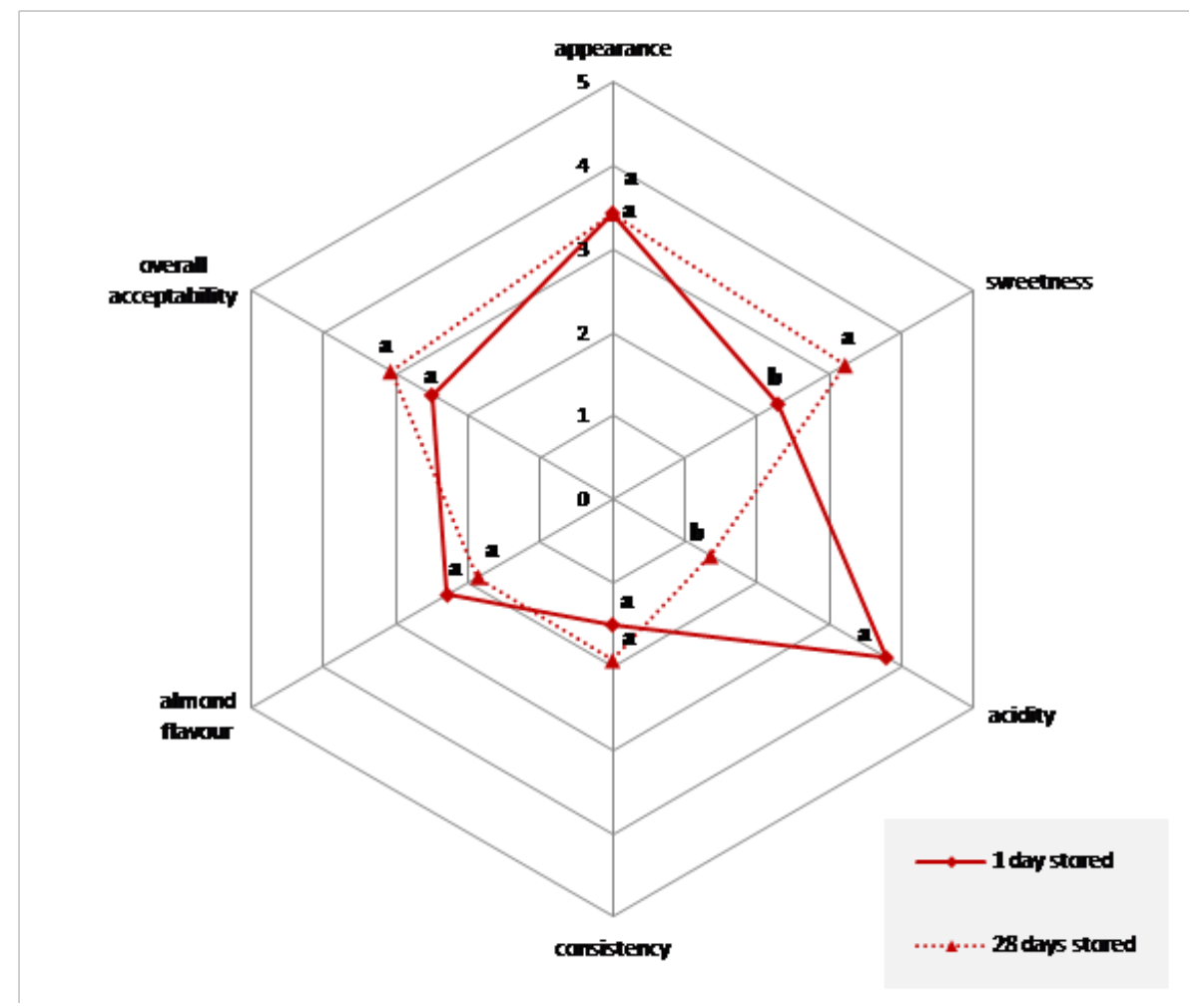

Figure 3: Panellists' scores for sweetness, acidity, consistency and overall acceptability of the fermented almond samples stored for 1 and 28 days at $4{ }^{\circ} \mathrm{C} .{ }^{a, b}$ Different letters in same attribute indicates significant differences between storage times $(\mathrm{p}<0.05)$

\section{Sensory analysis}

Figure 3 shows the scores of the attributes of appearance, sweetness, acidity, consistency and overall acceptability in the fermented almond samples tested by the members of the panel (after 1 and 28 storage days at $4^{\circ} \mathrm{C}$ ). Statistical differences between storage times were also included, showing the homogenous groups according to a LSD test (95\% confidence level).

Before tasting the fermented products, the panellists considered their appearance and consistency to be good, these not being attributes affected by the storage time $(\mathrm{p}<0.05)$.

Once the samples were tasted, the panellists appreciated the samples stored for 1 day as being significantly more acidic and less sweet than those stored for 28 days; this is in spite of the fact that the longer samples are stored, the more acidic they generally become. This controversial result could be explained by considering the synthesis of the volatile acetic acid brought about by the L. reuteri strain (Arskold et al., 2008), which is seen to transfer detectable vinegary, pungent and acidic odours into fermented products (Cheng, 2010). This acid is mainly formed at the beginning of fermentation and, after 28 storage days, the negative effect of acetic acid might have disappeared due to its volatilisation. The acceptability of the product was only rated as fair, and thus, some strategies could be designed to improve it. The judges found no significant differences in the overall acceptability of samples as affected by storage time $(\mathrm{p}<0.05)$. Further studies are needed to modify in some extent the mouthfeel and/or flavour of the fermented product, in order to ensure the developed 
product enjoys a wider consumer acceptance.

\section{Conclusions}

Raw almond milk is an unstable dispersion, which could be physically stabilised by the combination of low heat treatment with high homogenisation pressures. Almond milk is a proper matrix with which to obtain fermented derivative products, where starter bacteria are able to grow and survive. The fermentation process modified the inner structure of almond milk, converting it to a weak gel that was able to retain the water content of the almond milk. Moreover, the use of probiotic $L$. reuteri combined with $S$. thermophilus as starter inoculum permitted a high probiotic survival rate, both throughout the typical shelf life of yoghurt-like products (28 days) and after an in vitro digestion process, enhancing the possible health benefits that the developed product may impart to consumers due to the presence of $L$. reuteri. This new, non-dairy fermented functional food can be consumed by targeted groups such as vegetarians, the lactoseintolerant and those allergic to cow-milk protein. Nevertheless, despite the sensory results, some modifications in mouthfeel and/or flavour should be studied in order to improve its sensory acceptability and ensure that it enjoys a wide market acceptance.

\section{Acknowledgements}

This research has been carried out thanks to a project funded by the Universitat Politècnica de València (PAID-05-11-2740). This work was also supported by the "Conselleria d'Educació" of Valencian government, which awarded a grant to the author N. Bernat (ACIF/2011).

\section{References}

Arskold, E., Lohmeler-Vogel, E., Cao, R., Roos, S., Radstrom, P., \& van Niel, E. W. J. (2008). Phosphoketolase pathway dominates in lactobacillus reuteri atcc 55730 containing dual pathways for glycolysis. Journal of Bacteriology, 190(1), 206-212. doi:10.1128/JB.01227-07
Beisson, F., Ferte, N., Voultoury, R., \& Arondel, V. (2001). Large scale purification of an almond oleosin using an organic solvent procedure. Plant Physiology and Biochemistry, 39(7-8), 623-630. doi:10.1016/S09819428(01)01275-X

Bernat, N., Cháfer, M., González-Martínez, C., Rodríguez-García, J., \& Chiralt, A. (2014). Optimisation of oat milk formulation to obtain fermented derivatives by using probiotic lactobacillus reuteri microorganisms. Food Science and Technology International, 21(2), 145-157. doi:10.1177/ 1082013213518936

Buddington, R. (2009). Using probiotics and prebiotics to manage the gastrointestinal tract ecosystem. In Prebiotics and probiotics science and technology (pp. 1-31). Springer.

Casas, I. A. \& Mollstam, B. (1997). Treatment of diarrhea. Int. WO/1997046104 A1.

Cheng, H. (2010). Volatile flavor compounds in yogurt: a review. Critical Reviews in Food Science and Nutrition, 50(10), 938-950. doi:10.1080/10408390903044081

Coccorullo, P., Strisciuglio, C., Martinelli, M., Miele, E., Greco, L., \& Staiano, A. (2010). Lactobacillus reuteri (dsm 17938) in infants with functional chronic constipation: a double-blind, randomized, placebocontrolled study. Journal of Pediatrics, 157(4), 598-602. doi:10.1016/j.jpeds.2010. 04.066

Cruz, N., Capellas, M., Hernandez, M., Trujillo, A. J., Guamis, B., \& Ferragut, V. (2007). Ultra high pressure homogenization of soymilk: microbiological, physicochemical and microstructural characteristics. Food Research International, 40(6), 725-732. doi:10.1016/j.foodres.2007.01.003

Desrumaux, A. \& Marcand, J. (2002). Formation of sunflower oil emulsions stabilized by whey proteins with high-pressure homogenization (up to $350 \mathrm{mpa}$ ): effect of pressure on emulsion characteristics. International Journal of Food Science and Technology, 37(3), 263-269. doi:10.1046/j.13652621.2002.00565.x

Egert, S., Kratz, M., Kannenberg, F., Fobker, M., \& Wahrburg, U. (2011). Effects of high-fat and low-fat diets rich in monounsaturated 
fatty acids on serum lipids, ldl size and indices of lipid peroxidation in healthy nonobese men and women when consumed under controlled conditions. European Journal of Nutrition, 50(1), 71-79. doi:10.1007/ s00394-010-0116-9

FAO/WHO. (2001). Report on Joint FAO/WHO Expert Consultation on Evaluation of health and nutritional properties of probiotics in food including powder milk with live lactic acid bacteria. Retrieved from http : / / www . who . int / foodsafety / publications / fs_management / en/probiotics.pdf

Fiocchi, A., Brozek, J., Schuenemann, H., Bahna, S. L., von Berg, A., Beyer, K., ... Vieths, S. (2010). World allergy organization (wao) diagnosis and rationale for action against cow's milk allergy (dracma) guidelines. Pediatric Allergy and Immunology, 21 (21), 1125. doi:10.1111/j.1399-3038.2010.01068.x

Floury, J., Desrumaux, A., \& Lardières, J. (2000). Effect of high-pressure homogenization on droplet size distributions and rheological properties of model oil-inwater emulsions. Innovative Food Science and Emerging Technologies, 1(2), 127-134. doi:10.1016/S1466-8564(00)00012-6

Glahn, R. P., Lee, O. A., Yeung, A., Goldman, M. I., \& Miller, D. D. (1998). Caco-2 cell ferritin formation predicts nonradiolabeled food iron availability in an in vitro digestion caco-2 cell culture model. Journal of Nutrition, 128(9), 1555-1561.

Horwitz, W. (2000). Official methods of analysis of AOAC International. In Association of Official Analytical Chemists (Ed.). Gaithersburg.

Indrio, F., Riezzo, G., Raimondi, F., Bisceglia, M., Cavallo, L., \& Francavilla, R. (2008). The effects of probiotics on feeding tolerance, bowel habits, and gastrointestinal motility in preterm newborns. Journal of Pediatrics, 152(6), 801-806. doi:10.1016/j. jpeds.2007.11.005

International IDF Standard. (1997). Dairy starter cultures of Lactic acid Bacteria (LAB): Standard of identity. Brussels: International Dairy Federation.
Jones, J. L., Fernandez, M. L., McIntosh, M. S., Najm, W., Calle, M. C., Kalynych, C., ... Lerman, R. H. (2011). A mediterraneanstyle low-glycemic-load diet improves variables of metabolic syndrome in women, and addition of a phytochemical-rich medical food enhances benefits on lipoprotein metabolism. Journal of Clinical Lipidology, 5(3), 188-196. doi:10.1016/j.jacl.2011.03. 002

Li, Y.-Q., Chen, Q., Liu, X.-H., \& Chen, Z.-X. (2008). Inactivation of soybean lipoxygenase in soymilk by pulsed electric fields. Food Chemistry, 109(2), 408-414. doi:10. 1016/j.foodchem.2008.01.001

Liu, R. H. (2012). Health benefits of phytochemicals in whole foods. In Nutritional health (pp. 293-310). Springer.

Luengo, M. (2009). La almendra y otros frutos secos: castaña, pistacho, piñón, nuez. (Barcelona: Oceano AMBAR, Ed.).

Miniello, V. L., Brunetti, L., Tesse, R., Natile, M., Armenio, L., \& Francavilla, R. (2010). Lactobacillus reuteri modulates cytokines production in exhaled breath condensate of children with atopic dermatitis. Journal of Pediatric Gastroenterology and $\mathrm{Nu}$ trition, 50(5), 573-576. doi:10.1097/MPG. 0b013e3181bb343f

Pereda, J., Ferragut, V., Quevedo, J. M., Guamis, B., \& Trujillo, A. J. (2009). Heat damage evaluation in ultra-high pressure homogenized milk. Food Hydrocolloids, 23(7), 1974-1979. doi:10.1016/j.foodhyd. 2009.02.010

Saad, N., Delattre, C., Urdaci, M., Schmitter, J. M., \& Bressollier, P. (2013). An overview of the last advances in probiotic and prebiotic field. LWT-Food Science and Technology, 50(1), 1-16. doi:10.1016/j.lwt.2012. 05.014

Sanz, Y. \& Dalmau, J. (2008). Los probióticos en el marco de la nueva normativa europea que regula los alimentos funcionales. Acta Pediatr Esp, 66(1), 27-31.

Savino, F., Pelle, E., Palumeri, E., Oggero, R., \& Miniero, R. (2007). Lactobacillus reuteri (american type culture collection strain 55730) versus simethicone in the treatment of infantile colic: a prospective randomized 
Probiotic fermented almond "milk" $\mid 211$

study. Pediatrics, 119(1), E124-E130. Annual Meeting of the European-Society-forPediatric-Research, Siena, ITALY, AUG 31-SEP 03, 2005. doi:10.1542/peds.20061222

Tamime, A. Y. \& Robinson, R. K. (1999). Yoghurt: science and technology. Woodhead Publishing.

Walstra, P., Walstra, P., Wouters, J. T. M., \& Geurts, T. J. (2014). Dairy science and technology. CRC press.

Yada, S., Lapsley, K., \& Huang, G. (2011). A review of composition studies of cultivated almonds: macronutrients and micronutrients. Journal of Food Composition And Analysis, 24 (4-5, SI), 469-480. doi:10. 1016/j.jfca.2011.01.007

Zhang, H. K., Li, L. T., Tatsumi, E., \& Isobe, S. (2005). High-pressure treatment effects on proteins in soy milk. LWT-Food Science and Technology, 38(1), 7-14. doi:10.1016/ j.lwt.2004.04.007 